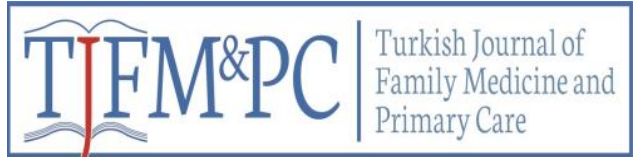

Original Research / Özgün Araştırma

\title{
A tobacco use survey among university students focusing on waterpipe use and relationship between first-tried tobacco product and becoming an established smoker Üniversite öğrencilerinde nargile odaklı tütün ürünleri kullanımı ve ilk denenen tütün ürünü ile tütün ürünü kullanıcısına dönüşme arasındaki ilişki
}

\author{
Recep Erol Sezer*1, Özlem Tanrı̈̈ver', Güliz Dirimen Arıkan², Mehtap Kacar ${ }^{l}$
}

\begin{abstract}
Objective: We aimed to describe tobacco use and tobacco related attitudes and perceptions among the Yeditepe University students with a special focus on waterpipe use, and to investigate the relationship between first-tried tobacco product and established smoking. Method: An anonymous questionnaire survey (a cross-sectional study) was conducted in the spring term of the 2014-15 academic year. Study subjects included all four year students $(n=354)$ of the faculties of medicine, pharmacy, dentistry, and health sciences of the Yeditepe University (Istanbul/Turkey). The response rate was 97.5\%. Results: The prevalence of current smoking was 53.5\% in males, $29.7 \%$ in females. Of the male students $58.6 \%$, among female students $32.1 \%$ smoked any tobacco product at least once in the last 30 days. While the proportion of those who have ever tried, even one puff, any tobacco product was $80.8 \%$ in males, $71.5 \%$ in females $(\mathrm{p}=0.075)$. The first-tried tobacco product was a cigarette among half of them, and a waterpipe product in the other half. The most tried tobacco product among females was a waterpipe product. While there was no relationship between the first-tried tobacco product and established smoking, of those who ever tried a tobacco product $74 \%$, and $45 \%$ became established smokers in males and females respectively $(\mathrm{p}<0.001)$. Of the 100 current daily smokers $100 \%$, and of the 26 non-daily current smokers $73 \%$ were cigarette smokers. Of those who were current smokers, $69 \%$ had become an established smoker during their university years in females, and $55.5 \%$ in males. A significant relationship was found between frequency of going to a café and current smoking. Mostly stated factors attracting students to use waterpipe were "taste, smell or aroma of the waterpipe smoke", and "social ambiance with friends". Conclusion: The state of the tobacco use epidemic among the students was found alarming. For the university students their university years seem to be the most important period regarding starting smoking. As a first-tried tobacco product, waterpipe appeared to be as important as cigarettes. Whether the first-tried tobacco product is cigarette or waterpipe, those who have ever tried them once, have a similar chance to become an established smoker. In the end, almost all of the smokers smoked cigarettes suggesting that waterpipe products feed cigarettes.
\end{abstract}

Key words: Tobacco use,cigarette smoking, waterpipe, first-tried tobacco product, university students

\section{ÖZET}

Amaç: Bu çalışmada, Yeditepe Üniversitesi öğrencilerinin, nargile odaklı olarak, tütün ürünlerini kullanma durumları ile bu konudaki algı ve tutumlarının tanımlanması amaçlanmıș, ayrıca ilk denemeyi sigara veya nargileyle yapma ile kullanıcıya dönüşme arasındaki ilişki incelenmiştir. Yöntem: Bu çalışma, isimsiz bir anket formunun Yeditepe Üniversitesi Tıp, Eczacılık, Diş ve Sağlık Bilimleri fakülteleri dördüncü sınıf öğrencileri tarafından doldurulmasına dayalı kesitsel bir çalışmadır. Bu fakültelerin 4. Sınıf öğrencilerinin tümü $(\mathrm{n}=354)$ çalışmaya dahil edilmeye çalışılmış, cevaplama oranı \%97,5 $(\mathrm{n}=345)$ olarak gerçekleşmiştir. Anket uygulaması, 20142015 Akademik Yılı Bahar Dönemi’nde yapılmıştır. Bulgular: Tütün ürünü halen kullanım oranı erkek öğrencilerde \% $\% 3,5$, kız öğrencilerde \%29,7, son otuz günde en az bir kez herhangi bir tütün ürün kullanma oranı erkek ve kız öğrencilerde sirasıyla \%58,6 ve $\% 32,1$ olarak bulunmuştur. Herhangi bir tütün ürününü yaşam boyu en az bir kez denemiş olma oranı erkeklerde \% $\% 0,8$, kızlarda \%71,5 $(\mathrm{p}=0,075)$ olarak saptanmıştır. İlk denemelerin yarısı sigara ile diğer yarısı nargile ile olmuştur. Kızlarda en çok denenen ürün nargiledir. İlk denenen ürünün sigara veya nargile olması ile kullanıcıya dönüşme arasında bir ilişki bulunamamıştır. Hangi ürün ile ilk denemesini yapmış olursa olsunlar bir kez denemiş olanların önemli bir bölümü (erkeklerde \%74, kızlarda \%45, p<0,001) kullanıcı olarak saptanmıștır. Halen her gün kullanan 100 öğrencinin \%100’ü, ara sıra kullanan 26 öğrencinin \% 73 ’ü sigara kullanıcısıdır. Halen tütün ürünü kullanan kızların en azından \%69'unda, erkeklerin \%55,5'inde kullanıcıya dönüşme (başlama) üniversitedeyken gerçekleşmiştir. Öğrencilerin kafeye gitme sıklığı ile tütün ürünü kullanıcısı olmaları arasında anlamlı bir ilişki saptanmıştır. Nargile içmeyi çekici kılan nedenler olarak en çok, "tadı, kokusu, aroması" ve "kafede sosyal atmosfer, arkadaşlarla birliktelik" ifade edilmiştir. Sonuç: Öğrencilerde tütün salgını endişe verici düzeyde olup, üniversite yılları, başlamada önemli bir dönem olarak ortaya çıkmıştır. Nargile, ilk denemelere sigara kadar aracılık etmektedir. Bu ürünleri bir kez denemiş olanlar, ilk denemeyi hangi ürünle yapmış olurlarsa olsunlar aynı düzeyde kullanıcıya dönüşmekte ve sonunda sigara kullanıcısı olmaktadırlar.

Anahtar kelimeler: Tütün kullanımı, sigara, nargile, ilk denenen ürün, üniversite öğrencileri

Received Date / Geliş Tarihi: 04.02.2018 Accepted Date / Kabul Tarihi: 24.04.2018

${ }^{1}$ Yeditepe Üniversitesi Tıp Fakültesi, İstanbul, ${ }^{2}$ Yeditepe Üniversitesi Sağlık Bilimleri Fakültesi

*Address for Correspondence / Yazışma Adresi: Recep Erol Sezer, Yeditepe Üniversitesi Tıp Fakültesi, İstanbul-TÜRKIYY Email: recep.erol.sezer@gmail.com

Sezer RE, Tanrı̈̈ver Ö, Arıkan GD, Kacar M. Üniversite öğrencilerinde nargile odaklı tütün ürünleri kullanımı ve ilk denenen tütün ürünü ile tütün ürünü kullanıcısına dönüşme arasındaki ilişki. TJFMPC, 2018;12 (4):281-287.

DOI: $10.21763 /$ tjfmpc.465766 


\section{GİRIŞ}

Dünya Sağlık Örgütü'ne göre Dünya'da halen yaklaşı1k 1,1 milyar kişi sigara veya diğer tütün ürünlerini kullanmakta ve her yıl bu nedenle 7,2 milyon kişi vakitsiz ölmektedir. ${ }^{1}$ Türkiye, tütün kontrolü alanında önemli ve dikkati çeken ilerlemeler sağlamayı başarmış, 2004 yılı sonrasında Tütün Kontrolü Çerçeve Sözleşmesini en iyi hayata geçiren ülkeler arasında sayılmıştır. ${ }^{2}$ Buna rağmen, Türkiye'nin 15 yaş ve üzeri sigara kullanım oranlarında kararlı bir düşme eğilimi henüz ortaya çıkmamıştır. Türkiye İstatistik Kurumu Sağlık Araştırması, 15 yaş ve üzeri için tütün ürünleri kullanım oranlarını 2014 yılında \%32,5, 2016 yılında \% 30,6 olarak tahmin etmiştir. ${ }^{3} \mathrm{Bu}$ değer, Türkiye Küresel Yetişkin Tütün Araştırmalarında 2008'de \% 31,3, 2012'de \% 27,1 olarak bildirilmiştir. ${ }^{4,5}$

Geçtiğimiz on yılda yaşanan değişikliklerle üniversitelerde bina içi kapalı alanlar önemli ölçüde dumansızlaştırılmış, fakat bina kapıları önleri yaygın olarak sigara içme yerlerine dönüşmüştür. Üniversite kampüslerinin çevresi, önlerinde ve içinde sigara ve nargile içilen, açılır kapanır bölmeleri olan kafeler ve nargile kafelerle dolmuş, üniversite gençlerini hedef alan bir aromatik nargile salgını oluşturulmuştur. ${ }^{6}$ Çalışmalarda sigara içmeyen veya içmemiş bazı kişilerin veya öğrencilerin nargileye başladıkları bildirilmiştir. ${ }^{7,8}$

Üniversite öğrencileri, yaşları ve aralarındaki yoğun etkileşim nedenleriyle sigaraya başlama yönünden önemli bir risk grubu olup endüstrinin hedefindedirler. $\mathrm{Bu}$ nedenle üniversite gençlerinin tütün ürünlerinden korunması özel bir çabayı gerektirir. Kendini koruyabilen üniversite mezunu gençler toplumun bu konuda şekillenmesine de anlamlı katkı sağlayabilir. Bu konuda ABD'de başlayan ve üniversite kampüslerinin önemli bölümünde hayata geçirilen, açık ve kapalı alanlariyla kampüslerin tümüyle dumansızlaştırılması politikası önemli bir gelişmedir. ABD'de Nisan 2018 itibariyle 2164 üniversite kampüsü \%100 dumansızlaştırılmıştır. ${ }^{9}$ Fakat ülkemizde bu konuda henüz önemli adımlar atılamamıştır.

$\mathrm{Bu}$ çalışmada, Yeditepe Üniversitesi öğrencilerinin, nargile odaklı olarak, tütün ürünlerini kullanma durumlarının, bazı algı ve tutumlarının tanımlanması amaçlanmaktadır. Kullanma durumu, tütün ürünlerinin her biri için denemeyi, deneme yaşını, ilk denenen tütün ürününü, kullanıcıya dönüşme durumunu, halen kullanım durumunu ve halen kullanılan tütün ürünlerini ve bunlar arasındaki ilişkileri kapsamaktadır. Bu bağlamda, "İlk denemenin sigara veya nargile olması ile kullanıcıya dönüşme arasında bir ilişki var mıdır?” sorusuna da cevap aranmıştır. $\mathrm{Bu}$ soru, yeterince incelenmemiş bir soru olup üzerinde çalışılmaya devam edilmektedir. ${ }^{10,11}$

Tutumlardan üzerine odaklanılan konular, öğrencilerin algılarıyla nargilenin bağımlık yapıcı ve zararlı etkisinin sigarayla karşılaştırılması, öğrencilerin kahve veya kafeye gitme alışkanlıkları, ve kafelerdeki tütün dumanı konusundaki tehlike algıları ve nargile içimine çeken nedenler olmuştur.

\section{YÖNTEM}

$\mathrm{Bu}$ çalışma, isimsiz bir anket formunun Yeditepe Üniversitesi Tıp, Eczacılık, Diş ve Sağlık Bilimleri fakülteleri dördüncü sınıf öğrencileri tarafından doldurulmasına dayalı kesitsel bir çalışmadır. Bu fakültelerin 4. Sinıf öğrencilerinin tümü $(n=354)$ çalışmaya dahil edilmeye çalışılmış, cevaplama oranı \%97,5 $(n=345)$ olarak gerçekleşmiştir. Etik Kurul onayı ve Rektörlük izni alınmıştır. Anket uygulamas1, 2014-2015 Akademik Y1l Bahar döneminde yapılmıştır.

Denenen tütün ürünleri, “Aşağıdaki ürünleri içmeyi bir çekim bile olsa denediniz mi?" sorusu ile anlaşılmaya çalışılmıştır. Bu sorunun cevap seçenekleri, sigara, nargile, pipo, puro ve diğer bir tütün ürünü (belirtiniz: ............) olmuştur. Denenen her ürün için deneme yaş1 sorulduğu gibi, ilk denenen ürünün hangisi olduğu da sorgulanmıştır. Her ürün için son otuz günde en az bir kez kullanma durumu, halen tütün ürünü kullanma durumu, günde veya haftada ortalama kullanma miktarı sorgulandığı gibi "Şimdiye kadar içtiğiniz toplam tütün ürünü sayısı 100 sigara veya eş değeri olmuş mudur?" sorusu da sorulmuştur. Bu sorulara ve ilgili literatüre dayalı olarak halen kullanım durumu; "halen kullananlar (current smokers), bırakmış olanlar (former smokers) ve kullanmamıs olanlar (never smokers) kategorilerini içermiştir. Halen kullananlar veya bırakmış olanlar kategorilerine girebilmek için yaşam boyu içilen toplam tütün ürünü sayısının en az 100 sigara veya eşdeğeri tütün ürünü düzeyine ulaşmas1 gerekmektedir. $^{12,13} \mathrm{Bu}$ iki kategori birlikte "Herhangi bir dönemde tütün ürünü kullanmış olanlar (ever smokers)" ş̧eklinde tanımlanmıştır. Halen kullananlar, kullanma özelliklerine göre, her gün kullananlar (daily smokers) ve her gün kullanmayanlar (non-daily smokers) alt gruplarına ayrılmışlardır. Halen kullananlar kategorisine geçme yani en az 100 sigara veya eşdeğeri tütün ürünü kullanımına ulaşma yaşı, başlama yaşı olarak kabul edilmiştir. ${ }^{11}$ Bunu saptamak üzere, bu düzeye ulaşmış olanlara ek olarak şu soru sorulmuştur: " $\mathrm{Bu}$ kullanım düzeyine ulaştığınızda kaç yaşındaydınız?”

"Nargile içenler cevaplayacak: Sizi nargile içimine çeken nedenleri özetle ifade eder misiniz?" açık uçlu sorusuyla bu konudaki görüşler anlaşılmaya çalışılmıştır. İçenlerin bırakma 
düşüncesi ve istekliliği yönünden tasnifi Prochaska'nın önerdiği sorular ve tasnif ölçütleriyle yapılmıștır. ${ }^{14}$ Katılımcılardan nargile ve sigaranın sağlık zararları ve bağımlılık yapıcı etkileri konularındaki düşüncelerini 0 ile 10 arasında bir notla ifade etmeleri istenmiştir. Bıraktıktan sonra geçen süre ve kafeye gitme sıklığı, sorgulanan diğer değişkenler olmuştur.

Anket formlarındaki veri kodlanarak SPSS tablosuna dönüştürülmüş, tasnif ve istatistik analiz SPSS yazılım programıyla yapılmıştır. Çapraz tablolara dayalı önemlilik değerlendirmeleri, ilgili tabloda özel bir açıklama yoksa ki-kare testi ile yapılmıştır.

\section{BULGULAR}

Ankete katılan 345 dördüncü sınıf öğrencisinin \%71,3'ü kızdır. Ortalama yaş: 23,3 $\pm 1,75$ (minimum:20, maksimum 29) olup cinsiyetle anlamlı düzeyde değişmemektedir.

Öğrencilerin halen tütün ürünü kullanma durumları Tablo 1'de sunulmuştur. Halen tütün ürünü kullanmakta olanların oranı: erkeklerde $\% 53,5$, kızlarda \% 29,7, toplamda \%36,5; bırakmış olanların oranı: erkeklerde $\% 5,1$, kızlarda $\% 2,4$, toplamda \%3,2; kullanmamış (içmemiş) olanların oranı ise: erkeklerde $\% 41,4$, k1zlarda $\% 67,9$, toplamda $\% 60,3$ olarak saptanmıștır. Halen kullanan 126 öğrencinin $\% 79,4$ 'ü $(n=100)$ her gün, \%20,6's1 $(n=26)$ bazı günler kullanmaktadır. Tütün ürünü kullanmakta olan 126 öğrencinin \%45,2’i $(n=57)$ hem sigara hem nargile kullanmakta, \%44,4'ü $(n=56)$ sadece sigara, \%4'ü $(n=5)$ sadece nargile, $\% 1,6$ 's1 $(n=2)$ sadece diğer tütün ürünleri, $\% 4,8$ 'i $(n=6)$ ise içinde sigaranın olduğu farklı bir kombinasyonla birden fazla tütün ürünü kullanmaktadır. Halen her gün kullanan 100 öğrencinin tamamı (\%100'ü) sigara içmekte olup, bunların \%49'u sigaraya ek olarak nargile, \%2'si ise sigaraya ek olarak diğer tütün ürünlerini kullanmaktadır. Ara sıra tütün ürünü kullanan 26 öğrencinin \%73'ü $(n=19)$ sigara kullanmaktadır. Kullanılan tütün ürünleri arasında elektronik sigara (e-sigara) hiç belirtilmemiştir.

Son otuz günde en az bir kez tütün ürünü kullanma yüzde oranları, cinsiyete göre Tablo 2'de görülmektedir. Son otuz günde herhangi bir tütün ürünü kullananların oranı, erkek öğrencilerde \%58,6, kız öğrencilerde \%32,1 olarak bulunmuştur. Anketi cevaplayanların bir çekim bile olsa tütün ürünü denemiş olma yüzde oranları cinsiyete göre Tablo 3'de yer almaktadır. Herhangi bir tütün ürününü en az bir kere denemiş olma oranı, erkek öğrencilerde $\% 80,8$, k1z öğrencilerde $\% 71,5$ olarak saptanmıştır $(\mathrm{p}=0.075)$. En çok denenmiş ürün, erkek öğrencilerde \%78,8'lik deneme oranı ile sigaradır, erkek öğrencilerin \% 74,7'ü nargile içmeyi de denemiştir. En çok denenen ürün kız öğrencilerde $\% 65,4$ oranı ile nargiledir, kız öğrencilerin \% 61,4'ü sigara içmeyi de denemiştir. Puro ve piponun denenme oranları, erkeklerde sirayla $\% 59,6$ ve $\% 36,4$ iken kızlarda aynı sirayla $\% 36,4$ ve $\% 11,4$ olarak bulunmuştur.

Herhangi bir tütün ürününü denemiş olan 256 öğrencinin 246's1 ilk denenen ürün ile ilgili soruyu cevaplamıștır. Cevaplayanların 124'ü (\%50) ilk denediği ürünün sigara olduğunu, 122'si (\%50) nargile olduğunu belirtmiştir. İlk denemeyi sigara ile yapmış öğrencilerin \%78'i daha sonra nargileyi de denemiştir. İlk denemeyi nargileyle yapmış öğrencilerin de \%84'ü daha sonra sigaray1 denemiştir. İlk deneme yaşı ortanca değeri 17 (çeyreklikler arası açıklık 3) olarak bulunmuştur.

Herhangi bir tütün ürünü denemiş olanların, ilk denenen ürünün nargile veya sigara olmasına, cinsiyete ve kullanıcıya dönüşme (en az 100 sigara eş değeri tütün ürünü kullanmış olma/başlama) durumlarına göre dağılımları Tablo 4'de görülmektedir. Erkeklerde, ilk denemesi sigara olan 43 öğrencinin 31'i (\%72'si), ilk denemesi nargile olan 34 öğrencinin 26's1 (\%76), toplamda hangi ürün olursa olsun bir kez denemiş olanların \%74'ü tütün ürünü kullanıcısına dönüşmüştür $(p=0,664)$. Kizlarda ise ilk denemesi sigara olan 81

öğrencinin 38'i (\%47'si), ilk denemesi nargile olan 88 öğrencinin 38 'i (\%43'ü), toplamda hangi ürün olursa olsun bir kez denemiş olanların \%45'i tütün ürünü kullanıcısına dönüşmüştür $(\mathrm{p}=0,626)$. Bir kez denemiş olanların kullanıcıya dönüşme (başlama) oranlar1, cinsiyete göre ise önemli düzeyde farklılaşmıștır (Kızlarda \%45, erkeklerde \%74, $\mathrm{p}<0,001)$.

Halen her gün kullananların tamamı (100 öğrenci), ara sıra kullanan 26 öğrencinin yedisi hariç tamamı sigara kullanıcısıdır. Halen tütün ürünü kullananlar arasında ilk denemesi sigara ile olan 63 öğrencinin \%84,1'i, ilk denemesi nargile ile 59 öğrencinin \%74,6'sı her gün sigara kullanmaktadır $(\mathrm{p}=0,192)$.

İlk denemede ve kullanıcıya dönüşmede (başlamada) üniversite döneminin yeri: İçilen tütün ürünü sayısının 100 adet sigara veya eşdeğeri tütün ürününe ulaştığı yaş, kullanıcı kategorisine geçiş (başlama) yaşı olarak düşünüldüğünde; sigara içmeye başlamış kızların \%69'unda, erkeklerin \%55,5'inde tütün ürünü kullanıcısına dönüşme (başlama) yaşı, üniversiteye başlama yaşından en az bir yıl daha büyüktür. Yani bu öğrenciler üniversitedeyken sigaraya başlamışlardır. 


\begin{tabular}{|c|c|c|c|c|}
\hline & $\begin{array}{l}\text { Halen } \\
\text { kullananlar }\end{array}$ & $\begin{array}{l}\text { Bırakmış } \\
\text { olanlar }\end{array}$ & $\begin{array}{l}\text { İçmemiş } \\
\text { olanlar }\end{array}$ & Toplam \\
\hline Erkek & $53(\% 53,5)$ & $5(\% 5,1)$ & $\begin{array}{c}41 \\
(\% 41,4) \\
\end{array}$ & 99 \\
\hline $\mathrm{K} 1 \mathrm{z}$ & $73(\% 29,7)$ & $6(\% 2,4)$ & $\begin{array}{c}167 \\
(\% 67,9) \\
\end{array}$ & 246 \\
\hline Toplam & $\begin{array}{c}126 \\
(\% 36,5)\end{array}$ & $11(\% 3,2)$ & $\begin{array}{c}208 \\
(\% 60,3)\end{array}$ & 345 \\
\hline \multicolumn{5}{|c|}{ Pearson Chi-Square: 20,7 , s.d.:2, $\mathrm{p}<0,001$} \\
\hline
\end{tabular}

\begin{tabular}{|c|c|c|c|c|}
\hline & $\begin{array}{l}\text { Erkek } \\
(\mathrm{n}=99)\end{array}$ & $\begin{array}{c}\mathrm{K} 1 \mathrm{Z} \\
(\mathrm{n}=246)\end{array}$ & $\begin{array}{l}\text { Toplam } \\
(\mathrm{n}=345)\end{array}$ & p-değeri \\
\hline $\begin{array}{l}\text { Herhangi bir } \\
\text { tütün ürünü }\end{array}$ & 58,6 & 32,1 & 39,7 & $\mathrm{p}<0,001$ \\
\hline Sigara & 55,6 & 29,7 & 36,8 & $\mathrm{p}<0,001$ \\
\hline Nargile & 23,2 & 6,9 & 11,6 & $\mathrm{p}<0,001$ \\
\hline $\begin{array}{l}\text { Diğer tütün } \\
\text { ürünleri* } \\
\text { (puro veya } \\
\text { pipo, sarma } \\
\text { tütün) }\end{array}$ & 4,0 & 0,8 & 1,7 & $\begin{array}{c}\mathrm{p}=0,059 \\
\text { (Fisher'in } \\
\text { exact testi } \\
\text { ile) }\end{array}$ \\
\hline \multicolumn{5}{|c|}{$\begin{array}{l}\text { E-sigara kullandığını ifade eden kimse çıkmamıştır. Pearson } \\
\text { Chi-square testi ile hesaplanmıștır. }\end{array}$} \\
\hline
\end{tabular}

\begin{tabular}{|c|c|c|c|c|}
\hline & $\begin{array}{c}\text { Erkek } \\
(\mathrm{n}=99)\end{array}$ & $\begin{array}{c}\mathrm{K} 1 \mathrm{z} \\
(\mathrm{n}=246)\end{array}$ & $\begin{array}{l}\text { Toplam } \\
(\mathrm{n}=345)\end{array}$ & p-değeri \\
\hline $\begin{array}{l}\text { Herhangi } \\
\text { bir tütün } \\
\text { ürünü }\end{array}$ & 80,8 & 71,5 & 74,2 & 0,075 \\
\hline Sigara & 78,8 & 61,4 & 66,4 & 0,002 \\
\hline Nargile & 74,7 & 65,4 & 68,1 & 0,094 \\
\hline Pipo & 36,4 & 11,4 & 18,6 & $<0,001$ \\
\hline Puro & 59,6 & 26,8 & 36,2 & $<0,001$ \\
\hline \multicolumn{5}{|c|}{$\begin{array}{l}\text { E-sigara kullandığını ifade eden kimse çıkmamıştır. Bir } \\
\text { öğrenci sarmalık tütün denediğini belirtmiştir. P değerleri, } \\
\text { Pearson Chi-square testi ile hesaplanmıştır. }\end{array}$} \\
\hline
\end{tabular}

\begin{tabular}{|c|c|c|c|}
\hline \multicolumn{4}{|c|}{$\begin{array}{l}\text { Table 4. Tütün ürünü denemiş olanla } \\
\text { ürüne ve kullanıcıya dönüşme durum } \\
\text { Kız öğrenciler }\end{array}$} \\
\hline $\begin{array}{l}\text { İlk } \\
\text { denenen } \\
\text { ürün }\end{array}$ & $\begin{array}{l}\text { Kullanıcıya } \\
\text { dönüşmüş } \\
\text { olanlar }\end{array}$ & $\begin{array}{l}\text { Kullanıcıya } \\
\text { dönüşmemiş } \\
\text { olanlar }\end{array}$ & Toplam \\
\hline Sigara & $38 \quad(\% 47)$ & $43 \quad(\% 53)$ & 81 \\
\hline Nargile & $38 \quad(\% 43)$ & $50 \quad(\% 57)$ & 88 \\
\hline Toplam & $76 \quad(\% 45)$ & $93 \quad(\% 55)$ & 169 \\
\hline \multicolumn{4}{|c|}{$\mathrm{p}=0,626$} \\
\hline \multicolumn{4}{|c|}{ Erkek öğrenciler } \\
\hline Sigara & $31 \quad(\% 72)$ & $12(\% 28)$ & 43 \\
\hline Nargile & $26 \quad(\% 76)$ & $8 \quad(\% 24)$ & 34 \\
\hline Total & $57 \quad(\% 74)$ & $20 \quad(\% 26)$ & 77 \\
\hline & \multicolumn{3}{|c|}{$\mathrm{p}=0.664$} \\
\hline \multicolumn{4}{|c|}{$\begin{array}{l}\text { Kullanıcıya (established smoker) dönüşmüş olma: Tütün } \\
\text { ürünü kullanma toplam miktarı } 100 \text { sigara eşdeğerine ulaşmış } \\
\text { olma. }\end{array}$} \\
\hline
\end{tabular}

Üniversiteye giriş yaşı ile başlama yaşını aynı yaş olarak ifade eden öğrencilerin oranı, erkeklerde \%11,1, k1zlarda \%14,7'dir. Bu öğrencilerin bir kısmının da üniversitedeyken başladıkları düşünülebilir.

\begin{tabular}{|c|c|c|c|c|}
\hline $\begin{array}{l}\text { Gidiş } \\
\text { siklığg }\end{array}$ & $\begin{array}{l}\text { Halen } \\
\text { kullananlar }\end{array}$ & $\begin{array}{l}\text { Bırakmış } \\
\text { olanlar }\end{array}$ & $\begin{array}{l}\text { Kullanmamış } \\
\text { olanlar }\end{array}$ & Toplam \\
\hline Hiç & $\begin{array}{c}1 \\
(\% 8,3)\end{array}$ & 0 & 11 & 12 \\
\hline Ara sira & $\begin{array}{c}75 \\
(\% 32,2) \\
\end{array}$ & 7 & 151 & 233 \\
\hline Her gün & $\begin{array}{c}50 \\
(\% 51)\end{array}$ & 4 & 44 & 98 \\
\hline Toplam & $\begin{array}{c}126 \\
(\% 36,7)\end{array}$ & 11 & 216 & 343 \\
\hline \multicolumn{5}{|c|}{$\begin{array}{l}\text { Yüzdeler satır yüzdeleridir. Bırakmış olanlar ve kullanmamıs ș } \\
\text { olanlar sütunları birleştirildikten sonra Pearson Chi- } \\
\text { square: } 14,84, \text { s.d: } 2, p=0,001\end{array}$} \\
\hline
\end{tabular}

Tütün ürünü denemiş olan kız ögrencilerin \%21,3'ünde ilk deneme yaş1, üniversiteye giriş yaşından en az bir yıl daha büyüktür, $\% 15$ 'inde ise üniversiteye giriş yaşı ile aynıdır. Tütün ürünü denemiş erkek öğrencilerde bu oranlar sırayla $\% 15,8$ ve $\% 11,1$ 'dir.

Öğrencilerin \%3,5'i kafeye gitmemekte, $\% 67,9$ 'u ara sira, $\% 28,6$ 's hemen hemen her gün gitmektedir. Kafeye gidiş sıklığının, kızlardaki ve erkeklerdeki dağılımı birbirine çok benzer bulunmuştur. Tablo 5 , kafeye gidiş sıklığı ve tütün ürünü kullanımı arasındaki ilişkiyi göstermektedir. $\mathrm{Bu}$ tablodan görülebileceği gibi halen tütün ürünü kullanmakta olanların oranı, kafeye hiç gitmeyenlerde $\% 8,3$, ara sira gidenlerde $\% 32,2$, her gün gidenlerde $\% 51$ 'dir, $\mathrm{p}=0,001$.

"Sizi nargile içimine çeken nedenleri ifade eder misiniz?" sorusuna verilen açık uçlu yanıtlar tasnif edilmiş ve belirtilme sayılarıyla şu başlıklarda toplanmıştır: Tadı, kokusu, aroması: 38; Kafede sosyal atmosfer, arkadaşlarla birliktelik:11; Yenilik, farklı bir şey: 8; Keyif: 6; Merak:5; Sigaradan daha az zararlı olması:2. Sigara ve nargileye ögrencilerin verdiği zararlı olma düzeyi notu ( 0 zararsız - 10 en zararl1) ortalamaları, sirayla 8,6 ve 8,76 olarak hesaplanmıştır. (Eşleştirilmiş t değeri:1,365, s.d:293, $\mathrm{p}=0,17)$. Öğrencilerin sigara ve nargileye verdikleri bağımlılık yapma düzeyi notu ( 0 bağımlılık yapmaz - 10 bağımlılık yapıcı etkisi en yüksek) ortalaması, sigara için 8,6, nargile için 5,8 olarak hesaplanmıştır (Eşleştirilmiş $\mathrm{t}$ değeri:15,2, s.d:271, $\mathrm{p}=0,001$ ). "Evinizde nargile var mı" sorusuna $12 \quad(\% 3,7)$ öğrenci evet cevabı vermiş̧tir.

Halen içenlerin Prochaska'nın bırakma yönündeki değişim aşamalarına göre dağılımı: Halen içen ve ilgili soruları tam olarak yanıtlayan 121 öğrencinin 53'ü (\%43,8'i) bırakmayı düşünmeme, 48 'i $(\% 39,7)$ bırakmayı düşünme ve 20'si $(\% 16,5)$ bırakma hazırlığı aşamasındadır.

"Gittiğiniz kafelerin kapalı alanlarında tütün içilmesine tepkiniz aşağıdakilerden hangisidir?" sorusuna cevap veren 336 öğrencinin 138 'i $(\% 41,1)$ "Zarar göreceğim için çok endişe ediyorum, 131'i (\%39) "Duman arttığında zarar 
görebileceğimi düşünüyorum”, 67'si $(\% 19,9)$ “Bir endişem olmuyor” seçeneklerini işaretlemişlerdir.

\section{TARTISSMA}

Öğrencilerin saptanan tütün ürünlerini halen kullanım oranları (erkeklerde \%53,5, kızlarda \%29,7), Türkiye Sağlık Araştırması'nın 15-24 ve 25-34 yaş grupları için bulduğu oranlardan daha yüksektir. Türkiye Sağlık Araştırması 2014, diğer yıllardan $(2010,2012,2016)$ daha yüksek tütün ürünleri kullanımı prevalans değerleri bildirmiştir: erkeklerde 15-24 yaş grubunda \%31,4, 25-34 yaş grubunda $\% 51,2$, kızlarda $15-24$ yaş grubunda $\% 5,7$, 25-34 yaş grubunda \%18,8. ${ }^{3}$ Yeditepe Üniversitesi öğrencilerinde saptadığımız değerler, her iki cinsiyet için de, hekim, eczacı, diş hekimi ve diğer sağlık profesyoneli olacak bu öğrenciler için aldıkları eğitimle uyumlu olmayan bir yüksekliği yansıtmaktadır. Yeditepe Üniversitesinde yapılan başka bir sigara kullanımı prevalans çalışması, 2010 yılında, aynı grup fakülte öğrencileri için sigara içme oranını \%28,7, diğer fakülte ve yüksekokul öğrencileri için $\% 44$ olarak bildirmişti. ${ }^{15} \mathrm{Bu}$ karşılaştırma üniversitede tütün ürünü kullanım salgınının bir düzelme olmaksızın sürdüğünü göstermektedir. Son otuz günde herhangi bir tütün ürünü kullanım oranları, halen kullanım oranlarından belirli ölçüde daha yüksek çıkmıştır. Halen kullanım oranı, erkek öğrencilerde $\% 53,5, \mathrm{kız}$ öğrencilerde \%29,7 iken, son otuz günde en az bir kez herhangi bir tütün ürün kullanma oranı erkek ve k1z öğrencilerde sirasıyla \%58,6 ve \%32,1 bulunmuştur. $\mathrm{Bu}$ bulgu, tütün ürünü kullanım prevalans değerlerinin karşılaştırılmasında, prevalansın nasıl ölçüldüğünün önemini göstermektedir.

Son otuz günde en az bir kez nargile kullanmış olma oranı, çalışmamızda erkeklerde $\% 23,2$, kılarda \%6,9 bulunmuş olup, nargile salgınının durumu hakkında bir fikir vermiştir. Türkiye'deki tıp fakültelerinin üçüncü sınıflarını temsil eden bir örneklemde gerçekleștirilen bir çalışmada son bir ayda nargile kullanmış olanların oranı, kızlarda \%13,1 [\%95 Güven aralığı (GA): $\% 10,9-\% 15,3]$; erkeklerde \%21,4 (\%95 GA: \%18,6 - \%24,2) olarak bildirilmiştir. ${ }^{16}$ Dokuz üniversitenin dördüncü sınıf öğrencileri üzerinde yapılan bir nargile prevalans araştırmasında, nargile prevalans oranları erkekler için \%33,1, kızlar için \%16,9 olarak bildirilmiştir. ${ }^{17}$ İstanbul'da 2012 y1lında yapılan ve İstanbul'un 10.sınıf öğrencilerini temsil eden bir çalışmada son otuz günde en az bir kez nargile kullanmış olma oranı erkeklerde \%24,8, kızlarda $\%$ 12,5 olarak bildirilmiştir. ${ }^{18}$ Bizim çalışmamızda bulduğumuz oran, bildirilen bu değerlerden düşüktür.

Tablo 3'de görüldüğü gibi erkeklerde sigara $\% 78,8$, kızlarda nargile $\% 65,4$ oranlarıyla en çok denenen ürünler olmuşlardır. İlk denenen tütün ürünü öğrencilerin yarısında sigara, yarısında nargile olarak saptanmıştır. Hem erkeklerdeki hem de kızlardaki yüksek nargile deneme oranları, nargile pazarlama çalışmalarının amacına ulaştığını düşündürmektedir. Benzer bir gelişme ABD'deki üniversite öğrencileri için de bildirilmiștir. ${ }^{10,19} \mathrm{Bu}$ durum nargile kafelerin gençlere ulaşmada nasıl etkili iş gördüğünü düşündürmektedir, zira nargile istisnalar dışında sadece kafelerde içilmektedir. Evinde nargilesi olduğunu söyleyen öğrenci sayısı sadece 12'dir. Öğrencilerin kafeye gitme sıklıkları cinsiyete göre değişmemekte olup \%67,9'u ara sıra, $\% 28,6$ 's1 neredeyse her gün kafeye gitmektedir. Bu bulgu, kafelerin, üniversite öğrencileri için önemli bir yaşam alanı olduğunu düşündürmektedir.

$\mathrm{Bu}$ çalışmada ilk denenen ürünün sigara veya nargile olmasının kullanıcıya dönüşme oranını etkilemediği bulgusu ortaya çıkmıştır. Her iki cinsiyette de bir kez denemiş olanların önemli bir bölümü (erkeklerde \%74'ü, kızlarda \%45'i) kullanıcıya dönüşmektedir. Bu durum, kullanıcılığa giden yolda, sigara ve nargilenin aynı etkiyi sağlayan birbirinin yerini tutan ürünler olduğunu, kadın cinsiyetin ise erkek cinsiyete kıyasla koruyucu bir faktör gibi iş gördüğünü akla getirmektedir. Kadın cinsiyetle ilgili bu koruyuculuk, toplumsal değer yargıları ve kültürel özelliklerle bağlantılı olabilir. İlk denemesini sigara ile yapmış olanların \%78'inin daha sonra nargileyi de denemiş olması; benzer biçimde ilk denemesini nargileyle yapmış olanların \%84'ünün daha sonra sigarayı da denemiş olması, bir kez denemiş olmanın başlamadaki önemini düşündürdüğü gibi diğer ürünü denemeyi de kolaylaştırdığını düşündürmektedir. $\mathrm{Bu}$ anlamda sigara ve nargilenin etkileri benzer gibi görünmektedir. Sigarayı hiç denememiş öğrencilerin izlenmesine dayalı bir izleme çalışması, çalışma başında nargile kullananların (son otuz günde en az bir kez nargile içenlerin), kullanmayanlara göre izleme döneminde sigaraya daha fazla başladığını bildirmiştir. $^{7}$ Başka bir çalışma, henüz tütün kullanıcısına dönüşmemiş 18-24 yaş grubundaki gençler arasında izleyen bir yıl içinde sigara içebileceğini ifade etme oranını, nadiren nargile içenlerde, nargile denememişlere göre anlamlı düzeyde yüksek bulmuştur. ${ }^{19}$ Nargileyi daha sık kullananlarda bu oran daha da yüksektir. Birbirinin denenmesini kolaylaştırma ve kullanıcıya dönüşmeye etkileri yönünden nargile - sigara karşılaştırılması izleme tipi çalışmalarla netleştirilmelidir.

Çalışmamızın bulguları, kullanıcıya dönüşmüş öğrenciler için kullanılan ana ürünün de sigaraya dönüştüğünü düşündürmektedir. Şöyle ki: hangi ürünle ilk denemelerini yapmış olurlarsa olsunlar, her gün kullananlar düzeyine ulaşmış 100 öğrencinin tamamı sigara kullanmakta olup, bunların yarısı sadece sigara içmektedir. Ara sıra 
kullanan 26 öğrencinin \%73'ü $(n=19)$ de sigara kullanmaktadır. Sutfin ve arkadaşları da sigara dışı diğer ürünlerin sigara kullanımını artırdığı düşüncesine ulaşmışlardır. ${ }^{11}$ Kafeye gitme sıklığ 1 ve tütün ürünü kullanıcısı olma arasında çalışmamızda saptanan ilişki, ilk denemelerin yarısının nargile ile olması bulgusuyla uyumlu olup, nargile kafelerin bu salgının gençlerdeki yayılımına önemli düzeyde katkı sağladığını akla getirmektedir. Kayseri'de yapılan bir nargile çalışmasında, nargile içenlerin büyük çoğunluğu nargileyi bir kafede, arkadaşlarıyla birlikteyken ve keyif için içtiklerini ifade etmişlerdir. ${ }^{7}$ Aynı çalışmada bağımlılık yapıcılık yönünden nargilenin sigaraya göre daha zayıf olduğu ifadesi, aynı konudaki diğer ifadelerden daha yaygın kabul görmüştür. Poyrazoğlu ve arkadaşlarının bu bulgusu, bizim çalışmamızın bağımlılık yönünden sigara ile nargileyi karşılaştıran bulgusuyla paraleldir. Bizim çalışmamız, nargilenin hastalık yapıcı etkisinin öğrenciler tarafından sigaranın hastalık yapıcı etkisine denk olarak algılandığını düşündürmektedir. Benzer karşılaştırmayı yapan bazı çalışmalara göre, nargilenin hastalık yapıcı etkisi sigaraya göre daha zayıf olarak, bazılarına göre de daha güçlü olarak algılanmaktadır. ${ }^{7,8,}$ 21-23 Çalışmamızın kafelerde duman altı olmanın endişe vericiliği konusundaki bulgusu kafeye gidenlerin yaklaşık \%60'ının tütün dumanının zararlı etkisini kanıksadığını veya ona aldırmadığını düşündürmektedir. Öğrencilerin duman altı olmayı kanıksamaları, nargile algıları (tat, koku, aroma, keyif, kafedeki sosyal atmosfer, arkadaşlarla birliktelik aracı, yeni ve farklı bir şey, merak, sigaradan daha az zararlı olmas1), ve kafelerle ilgili gözlenebilir bazı özellikler (kafelerde yarı açık yarı kapalı sigara içilebilir alanlar yaratılması, üniversite etrafının nargile kafelerle dolması) üniversite gençlerini hedef alan ve tütün salgınını destekleyici etki yapan yeni bir nargile işinin ve kültürünün oluşturulduğunu düşündürmektedir.

Sonuç: Üniversite öğrencilerinde tütün salgını endişe verici düzeyde olup, üniversite yılları, başlamada önemli bir dönem olarak ortaya çıkmıştır. $\mathrm{Bu}$ çalışmanın bulgularına göre nargile, ilk denemelere sigara kadar arac1lık etmektedir. Bu ürünleri bir kez denemiş olanlar, ilk denemeyi hangi ürünle yapmış olurlarsa olsunlar aynı düzeyde kullanıcıya dönüşmekte ve sonunda sigara kullanıcısı olmaktadırlar. Kafeler, yarattıkları kafe kültürüyle bu salgının önemli bir bileşeni gibi görünmektedir. Tütün kontrolü çalışmalarında üniversiteler ve çevrelerindeki kafelerle ilgili iyileştirmeler ivedilikle sağlanmalıdır.

\section{KAYNAKLAR}

1. Chan M. Ten Years in Public Health, 20072017. World Health Organization 2017. p.98
2. U.S. Department of Health and Human Services. The Health Consequences of Smoking - 50 Years of Progress. A Report of the Surgeon General. Atlanta, GA: U.S. Department of Health and Human Services, Centers for Disease Control and Prevention, National Center for Chronic Disease Prevention and Health Promotion, Office on Smoking and Health, 2014. Printed with corrections, January 2014. p.819-20

3. TUIK. Türkiye Sağlık Araştırması (Turkey Health Interview Survey) 2014, 2016. http://www.tuik.gov.tr/PreTablo.do?alt_id=109 5 (Erişim tarihi: 12.07.2018)

4. Sağlık Bakanlığı Temel Sağlık Hizmetleri Genel Müdürlüğü, Küresel Yetişkin Tütün Araştırması Türkiye Raporu. 2010. p.11.

5. Sağlık Bakanlığı Halk Sağlığı Kurumu Başkanlığı. Türkiye Küresel Yetişkin Araştırması Türkiye 2012. Ankara 2014. p.35

6. Sezer RE, Pıçak YK. Tütün mücadelesi için yeni bir tehdit: Aromatik nargile. Cumhuriyet Tip Dergisi 2011;33:133-43.

7. Poyrazoğlu S, Sarli S, Gencer Z, Günay O. Waterpipe (narghile) smoking among medical and non-medical university students in Turkey. Ups J Med Sci 2010; 115: 210-6.

8. Erbaydar NP, Bilir N, Yildiz AN. Knowledge, behaviors and health hazard perception among Turkish narghile (waterpipe)-smokers related to narghile smoking. Pak J Med Sci 2010; 26: 195200.

9. American Nonsmokers' Rights Foundation. Smokefree and Tobacco-Free U.S. and Tribal Colleges and Universities: April 1, 2018. Erişim tarihi: 14.06.2018. https://no-smoke.org/wpcontent/uploads/pdf/smokefreecollegesuniversi ties.pdf

10. Meier EM et al. Which nicotine products are gateways to regular use. American Journal of Preventive Medicine. Am J Prev Med 2015;48(1S1):S86-S93

11. Sutfin EL et al. First tobacco product tried:Associations with smoking status and demographics among college students. Addictive Behaviors. 51(2015)152-157

12. U.S. Department of Health and Human Services. The health benefits of smoking cessation. A report of the Surgeon General. Atlanta, GA: Office on Smoking and Health, 
Centers for Disease Control 1990. 628 p. (DHSS publication no. (CDC) 90-8416).

13. Mowery PD et al.. Progression to Established Smoking Among US Youths. Am J Public Health. 2004;94:331-337).

14. Prochaska JO, Goldstein MG. Process of smoking cessation. Implications for clinicians. Clin Chest Med 1991; 12: 727-35.

15. Akan H, Hayran O, Özcan M, Acar U. Üniversite öğrencileri arasında sigara içme sıklığg: Kesitsel bir çalışma. Türk Aile Hek Derg 2010; 14(2): 71-76.

16. Inand $1 \mathrm{~T}$ et al. Global health professional medical- student survey 2010. MKU, WHO, CDC. October 2010.

17. Ozcebe H et al. Smoking Water Pipe Habits of University Students and Related Sociodemographic Characteristics. TAF Prev Med Bull 2014;13(1):19-28

18. Evren C, Evren B, Bozkurt M. Tobacco use among 10th grade students in İstanbul and related variables. Asian Journal of Psychiatry. 2014;8:69-75.

19. Salloum RG, Haider RH, Barnett TE, Guo Y, Getz KR, Thrasher JF, Maziak W. Waterpipe tobacco smoking and susceptibility to cigarette smoking among young adults in the United States, 2012-2013. Prev Chronic Dis 2016;13:150505.DOI: http://dx.doi.org/10.5888/pcd13.150505

20. Soneji S, Sargent JD, Tanski SE, Primack BA. JAMA Pediatr. 2015 February ; 169(2): 129136. doi:10.1001/jamapediatrics.2014.2697.

21. Smith-Simone S, Maziak W, Ward KD, Eissenberg T. Waterpipe tobacco smoking: knowledge, attitudes, beliefs, and behavior in two U.S. samples. Nicotine Tob Res 2008; 10: 393-8.

22. Maziak W, Eissenberg T, Rastam S, Hammal F, Asfar T, Bachir ME, Fouad MF, Ward KD. Beliefs and attitudes related to narghile (waterpipe) smoking among university students in Syria. Ann Epidemiol 2004; 14: 646-54.

23. Varsano S, Ganz I, Eldor N, Garenkin M. Water-pipe tobacco smoking among school children in Israel: frequencies, habits, and attitudes. Harefuah 2003; 142: 736-41. 